\title{
Paracoccidioidomycosis of the Central Nervous System: $C T$ and MR Imaging Findings
}

\author{
(D) M. Rosa Júnior, (D)A.C. Amorim, (DI.V. Baldon, (D).A. Martins, (D).M. Pereira, (DR.P. Campos, (D)S.S. Gonçalves, (D)T.R.G. Velloso,
} (D). Peçanha, and (D) A. Falqueto

\begin{abstract}
BACKGROUND AND PURPOSE: Paracoccidioidomycosis is a fungal infection mainly caused by the thermodimorphic fungus Paracoccidioides. The purpose of our study was to demonstrate the neuroimaging findings from 24 patients with CNS paracoccidioidomycosis.

MATERIALS AND METHODS: We performed a retrospective analysis focusing on the radiologic characteristics of CNS paracoccidioidomycosis. The 24 selected patients underwent MR imaging and/or CT, and the diagnosis was made by the presence of typical neuroimaging features, combined with fungus isolation, a serologic test, or the presence of disseminated disease.

RESULTS: Headache was the most common neurologic symptom, while the pseudotumoral form was the most common pattern. The number of lesions ranged from 1 to 11 , with most localized on the frontal lobe with $>2$-cm lesions. CT showed mainly hypoattenuating lesions, whereas MR imaging demonstrated mainly hyposignal lesions on TIWI and T2WI. Furthermore, ring enhancement was present in most patients. The "dual rim sign" on SWI occurred in $100 \%$ of our patients with lesions of $>2 \mathrm{~cm}$.
\end{abstract}

CONCLUSIONS: The diagnosis of CNS paracoccidioidomycosis is difficult. Nevertheless, imaging examinations can play an important role in the diagnosis and evaluation of the disease.

ABBREVIATIONS: $\mathrm{PCM}=$ paracoccidioidomycosis; $\mathrm{CT}$ = computed tomography; $\mathrm{MRI}=$ magnetic resonance imaging; $\mathrm{CNS}=$ central nervous system; DSC = dynamic susceptibility contrast; DCE = dynamic contrast enhanced; rCBV = relative cerebral blood volume; Gd = gadolinium

$\mathbf{P}$ aracoccidioidomycosis (PCM) is a fungal infection, which is endemic in Latin America and is mainly caused by the thermodimorphic fungus Paracoccidioides spp, which primarily attacks the lungs and has a potential to disseminate to other organs. ${ }^{1}$ Recently described are 4 other species of the genus Paracoccidioides apart from $P$ brasiliensis: $P$ lutzii, $P$ restrepiensis, $P$ venezuelensis, and $P$ Americana. ${ }^{2,3}$

Paracoccidioides spp inhabits primarily the soil and causes autochthonous infection from southern Mexico to northern Argentina. ${ }^{4-6}$ Most reported cases (approximately $80 \%$ ) are from

Received June 19, 2019; accepted after revision July 25

From the Departments of Neuroradiology (M.R.J.) and Radiology (A.C.A., I.V.B., L.A.M., R.M.P.), Hospital Universitário Cassiano Antônio de Moraes da Universidade Federal do Espírito Santo, HUCAM/UFES/EBSERH, Vitória, Espírito Santo, Brazil; Department of Neuroradiology (R.P.C.), Hospital Meridional, Cariacica, Espírito Santo, Brazil; and Departments of Pathology (S.S.G.), Clinical Dentistry (T.R.G.V.), and Infectious Disease (P.P., A.F.), Universidade Federal do Espírito Santo, Vitória, Espírito Santo, Brazil.

Please address correspondence to Marcos Rosa Júnior, MD, PhD, Universidade Federal do Espírito Santo, UFES, Centro de Ciências da Saúde, Maruípe, 29043900, Vitória, Espírito Santo, Brazil; e-mail: marcosrosajr@hotmail.com

- Indicates open access to non-subscribers at www.ajnr.org

http://dx.doi.org/10.3174/ajnr.A6203
Brazil, and the rest are mainly from Venezuela, Colombia, and Argentina. ${ }^{6-14}$

The criterion standard for the diagnosis of PCM consists of demonstrating the presence of the fungus as multiple budding cells in clinical or tissue specimens. Nevertheless, serologic tests and imaging examinations such as CT, MR imaging, and x-rays also play an important role in the diagnosis and evaluation of the disease. , $^{1,-17}$

CNS involvement is more common than it was once believed, and the disease can affect the CNS, ranging from $1 \%$ to $27.27 \%$ of cases. ${ }^{18-25}$ Although the brain form of PCM is usually an outcome of hematogenous or lymphatic dissemination of a primary focus, it is not necessarily followed by disseminated PCM; in a few cases, it is the only location of the fungus in the body. ${ }^{26}$

Our purpose was to describe the clinical and radiologic data (CT and MR imaging) of 24 patients diagnosed with CNS PCM between 1978 and 2019. To the best of our knowledge, this is the largest imaging study of CNS PCM.

\section{MATERIALS AND METHODS}

This was a retrospective study, focusing on the radiologic characteristics of patients with CNS PCM attending the University Hospital Cassiano Antônio de Moraes, Federal University of 
Table 1: Epidemiologic and clinical characteristics

\begin{tabular}{lc}
\hline \multicolumn{1}{c}{ Characteristic } & Value \\
\hline Age & \\
Median (range) (yr) & $54(19-66)$ \\
Subgroup (No. of patients) (\%) & \\
$0-19$ & $1(4.1)$ \\
$20-39$ & $6(25.0)$ \\
$40-59$ & $11(45.8)$ \\
$\geq 60$ & $6(25.0)$ \\
Male sex (No.) (\%) & $24(100)$ \\
Neurologic symptoms (No. of patients) (\%) & \\
Headache & $8(33.3)$ \\
Epilepsy & $7(29.1)$ \\
Focal neurologic signs & $6(25.0)$ \\
Paresis & $5(20.8)$ \\
Paresthesia & $4(16.6)$ \\
Plegia & $2(8.3)$ \\
Dysarthria & $2(8.3)$ \\
Mental confusion & $2(8.3)$ \\
Head lump & $2(8.3)$ \\
Diplopia & $1(4.1)$ \\
Chorea & $1(4.1)$ \\
Vertigo & $1(4.1)$ \\
Absence of neurologic symptom & $2(8.3)$ \\
\hline
\end{tabular}

\section{Table 2: CT findings}

\begin{tabular}{|c|c|}
\hline Characteristic & Value \\
\hline \multicolumn{2}{|l|}{ Patterns (No. of patients) (\%) } \\
\hline Pseudotumoral & $21(87.5)$ \\
\hline Meningeal & $1(4.1)$ \\
\hline Pseudotumoral + meningeal (combined) & $2(8.3)$ \\
\hline Calcifications (No. of patients) (\%) & $0(0)$ \\
\hline Perilesional edema (No. of patients) $(\%)^{a}$ & $19(90.4)$ \\
\hline Hydrocephalus (No. of patients) (\%) & $6(25.0)$ \\
\hline Hemorrhage (No. of patients) (\%) & $3(13.0)$ \\
\hline \multicolumn{2}{|l|}{ No. of lesions $\mathrm{b}^{\mathrm{s}}$} \\
\hline Mean (range) & $3.0(1-11)$ \\
\hline \multicolumn{2}{|l|}{ Subgroup (No. of patients) (\%) } \\
\hline Single lesions & $9(39.1)$ \\
\hline $2-5$ & $11(47.8)$ \\
\hline $6-10$ & $2(8.6)$ \\
\hline$>10$ & $1(4.3)$ \\
\hline \multicolumn{2}{|l|}{ Lesion size (No. of patients) (\%) ${ }^{\mathrm{b}}$} \\
\hline$>2 \mathrm{~cm}$ & $15(65.2)$ \\
\hline \multicolumn{2}{|l|}{ Larger axial diameter of the major lesion ${ }^{\mathrm{b}}$} \\
\hline Mean (range) $(\mathrm{cm})$ & $2.6(0.3-5.6)$ \\
\hline \multicolumn{2}{|l|}{ CT attenuation (No. of patients) (\%) ${ }^{c}$} \\
\hline Hyperattenuating lesions & $11(20.7)$ \\
\hline Hypoattenuating lesions & $30(56.6)$ \\
\hline $\begin{array}{l}\text { Hypoattenuating center and hyperattenuating } \\
\text { margin }\end{array}$ & $12(22.6)$ \\
\hline \multicolumn{2}{|l|}{$\begin{array}{l}\mathrm{CT} \text { or MR imaging contrast enhancement (No. of } \\
\text { patients) (\%) }\end{array}$} \\
\hline Ring enhancement & $17(70.8)$ \\
\hline Nodular enhancement & $3(12.5)$ \\
\hline Ring and nodular enhancement & $3(12.5)$ \\
\hline Leptomeningeal enhancement & $1(4.1)^{\prime}$ \\
\hline
\end{tabular}

Espirito Santo, between 1978 to 2019. The 24 selected patients had MR imaging and/or CT scans, and the diagnosis was made by the presence of typical neuroimaging features, combined with
Table 3: Lesion sites

\begin{tabular}{lc}
\hline \multicolumn{1}{c}{ Characteristic } & Value \\
\hline Localization (No. of patients) (\%) & \\
Basal meningitis & $1(4.1)$ \\
Pachymeningitis & $1(4.1)$ \\
Skull & $2(8.3)$ \\
Parietal lobe & $7(29.1)$ \\
Occipital lobe & $6(25.0)$ \\
Frontal lobe & $9(37.5)$ \\
Temporal lobe & $5(20.8)$ \\
Cerebellum & $8(33.3)$ \\
Cingulate gyrus & $3(12.5)$ \\
Thalamus & $5(20.8)$ \\
Basal ganglia & $3(12.5)$ \\
Striatum & $1(4.1)$ \\
Globus pallidus & $1(4.1)$ \\
Caudate nucleus & $1(4.1)$ \\
Putamen & $1(4.1)$ \\
Corpus callosum & $2(8.3)$ \\
Hippocampus & $1(4.1)$ \\
Hypothalamus & $1(4.1)$ \\
Pons & $2(8.3)$ \\
\hline
\end{tabular}

fungus isolation, a serologic test, or the presence of disseminated disease.

The CT scans were performed with Aquilion ONE 64-slice (Toshiba Medical Systems, Tokyo, Japan) or Asteion single-section (Toshiba Medical Systems) scanners. Patients were studied with 1-, 5-, or 10-mm axial slices before and/or after administration of an intravenous iodinated contrast agent in a peripheral vein at a total dose of $1.5 \mathrm{~mL} / \mathrm{kg}$. Fourteen patients underwent CT before and after contrast, and 3 patients, without contrast administration.

The MR images were obtained in a $1.5 \mathrm{~T}$ Achieva (Philips Healthcare, Best, the Netherlands) or a $1.5 \mathrm{~T}$ Brivo (GE Healthcare, Milwaukee, Wisconsin), with a specific head coil model with 8 channels, with T1-weighted, T2-weighted, FLAIR, DWI, $2_{2}^{*}$, and $\mathrm{T} 1$ postcontrast images. Intravenous administration of $0.1 \mathrm{mmol} / \mathrm{kg}$ of gadolinium-based contrast agent through the antecubital vein was performed for all patients. The MR imaging parameters were the following-Achieva: T1-weighted: $\mathrm{TR}=547.8-623 \mathrm{~ms}, \mathrm{TE}=12.8-15 \mathrm{~ms}$, section thickness $=$ $5.0 \mathrm{~mm}$, matrix $=528 \times 528-328 \times 271 ;$ T2-weighted: $\mathrm{TR}=$ $4572.5-4631 \mathrm{~ms}, \mathrm{TE}=100 \mathrm{~ms}$, section thickness $=5.0 \mathrm{~mm}$, matrix $=704 \times 704-328 \times 253$; FLAIR: TR $=11,000 \mathrm{~ms}$, TE $=$ $140 \mathrm{~ms}$, TI $=2800$, section thickness $=5.0 \mathrm{~mm}$, matrix $=640 \times$ 640-256 × 156; DWI: TR $=4583-6596.3 \mathrm{~ms}, \mathrm{TE}=79-88.2 \mathrm{~ms}$, section thickness $=3.5 \mathrm{~mm}$, matrix $=512 \times 512-192 \times 114 ; \mathrm{T}^{*}$ : $\mathrm{TR}=588-609 \mathrm{~ms}, \mathrm{TE}=13.8 \mathrm{~ms}$, section thickness $=5.0 \mathrm{~mm}$, matrix $=512 \times 512-232 \times 183 ;$ SWI: TR $=22.6 \mathrm{~ms}, \mathrm{TE}=32.5 \mathrm{~ms}$, section thickness $=2.0 \mathrm{~mm}$, matrix $=448 \times 448$; T1 3D saggital postcontrast fast-field echo: $\mathrm{TR}=12.4 \mathrm{~ms}, \mathrm{TE}=5946 \mathrm{~ms}$, section thickness $=1 \mathrm{~mm}$, matrix $=288 \times 288$; Brivo: T1-weighted: $\mathrm{TR}=$ $728 \mathrm{~ms}, \mathrm{TE}=3 \mathrm{~ms}$, section thickness $=5.5 \mathrm{~mm}$, matrix $=416 \times$ 192; T2-weighted: $\mathrm{TR}=3625 \mathrm{~ms}, \mathrm{TE}=122 \mathrm{~ms}$, section thickness = $4.5 \mathrm{~mm}$, matrix $=416 \times 192$; DWI: TR $=7309 \mathrm{~ms}, \mathrm{TE}=117 \mathrm{~ms}$, section thickness $=4.5 \mathrm{~mm}$, matrix $=128 \times 128 ; \mathrm{T}^{*}$ : $\mathrm{TR}=434$ $\mathrm{ms}, \mathrm{TE}=15.8 \mathrm{~ms}$, section thickness $=4.5 \mathrm{~mm}$, matrix $=320 \times 224$; FLAIR: $\mathrm{TR}=10,000 \mathrm{~ms}, \mathrm{TE}=110 \mathrm{~ms}$, section thickness $=4.5 \mathrm{~mm}$, matrix $=288 \times 192 ; \mathrm{T} 13 \mathrm{D}$ saggital postcontrast: $\mathrm{TR}=7.9 \mathrm{~ms}$, $\mathrm{TE}=2.6 \mathrm{~ms}$, section thickness $=2.0 \mathrm{~mm}$, matrix $=288 \times 224$. 


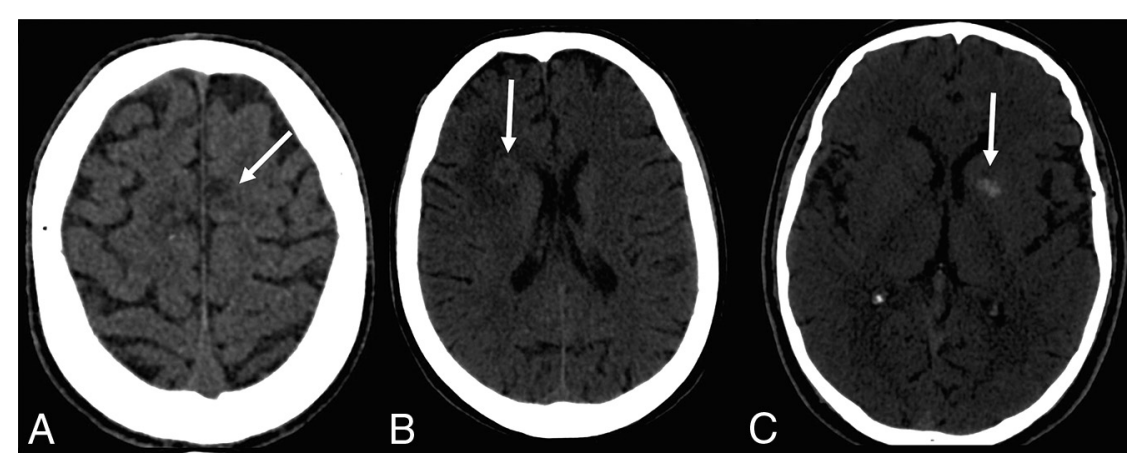

FIG 1. Brain CT showing different presentations of the lesions. $A$, Hypoattenuating lesions. $B$, Hypoattenuating lesions with a hyperattenuating halo. $C$, Hyperattenuating lesions.

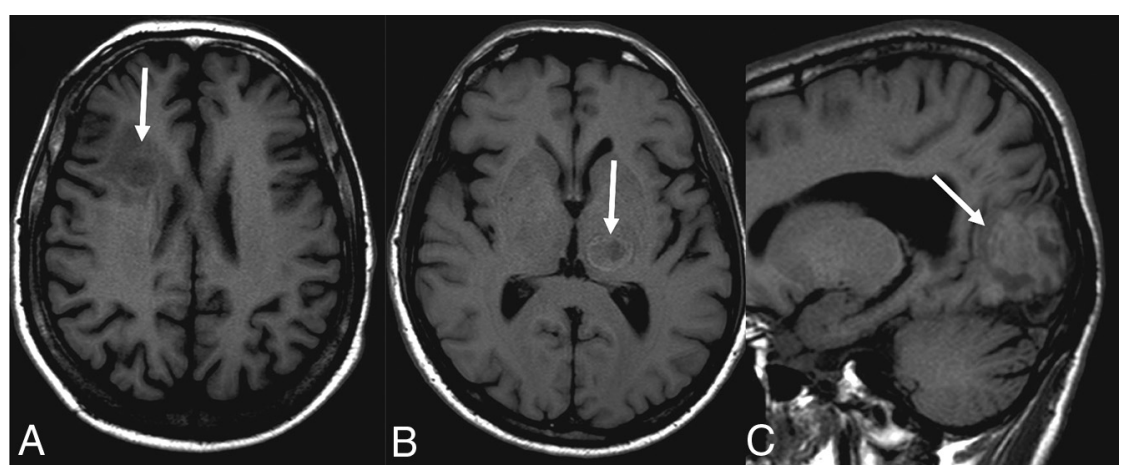

FIG 2. Signal on the T1-weighted images: hypointense lesion $(A)$, lesion with hypointense center and hyperintense halo $(B)$, and hyperintense lesion $(C)$.

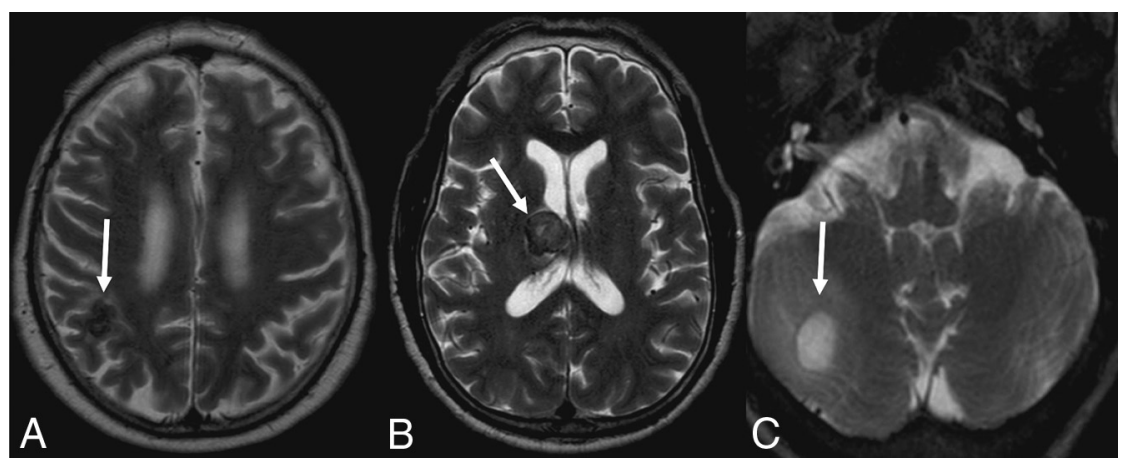

FIG 3. T2-weighted images show a hypointense lesion $(A)$, a heterogeneous signal $(B)$, and a hyperintense lesion (C).

Five patients also underwent SWI, 2 patients underwent perfusion DSC and dynamic contrast-enhanced imaging, and 2 patients underwent spectroscopy studies, only with qualitative analyses.

\section{Dynamic Contrast-Enhanced MR Imaging}

A power injector was used to administer a bolus of gadoliniumbased contrast agent at a dose of $0.05 \mathrm{mmol} / \mathrm{kg}$ and rate of $5 \mathrm{~mL} / \mathrm{s}$. The kinetic enhancement of tissue before and after contrast injection was obtained using a 3D-T1weighted fast-spoiled gradient-echo sequence $(\mathrm{TR}=5.5 \mathrm{~ms}, \mathrm{TE}=1.3 \mathrm{~ms}$, section thickness $=5 \mathrm{~mm}$, flip angle $=12^{\circ}$, FOV $=240 \times 177 \times 125 \mathrm{~cm}$, matrix $=$ $108 \times 100)$ and consisted of 25 images in the axial plane. Ten phases for preinjection time delay and 30 phases for postinjection were obtained.

DSC-PWI was performed with a gradient-recalled $\mathrm{T} 2{ }^{*}$-weighted echo-planar imaging sequence. The imaging parameters were as follows: TR/TE $=2085 / 40 \mathrm{~ms}$, flip angle $=75^{\circ}$, section thickness $=5 \mathrm{~mm}$, intersection gap $=0.5 \mathrm{~mm}, \mathrm{NEX}=1.0$, FOV $=240 \times 240 \mathrm{~mm}$. During the first 3 phases, images were acquired before injecting the contrast material to establish a baseline. When the scan was in the fourth phase of DSC-PWI, a bolus of gadolinium-based contrast agent at a dose of $0.25 \mathrm{mmol} / \mathrm{kg}$ of body weight and $5 \mathrm{~mL} / \mathrm{s}$ was injected intravenously with an MR imaging-compatible power injector. After we injected a bolus of the contrast material, a $20.0-\mathrm{mL}$ bolus of saline was administered at the same injection rate. The series had 25 sections with 60 phases.

Single-voxel spectroscopy was acquired encompassing the annular enhancement area and the center nonenhancement area after contrast administration with the following parameters: point-resolved spectroscopy sequence, axial acquisition plane, $\mathrm{TE}=35$ and $144 \mathrm{~ms}, \mathrm{TR}=541 \mathrm{~ms}$, number of acquisitions $=64$, spectral resolution $=4096$ points, voxel size $=$ $8 \mathrm{~cm}^{3}(2 \times 2 \times 2 \mathrm{~cm})$.

We evaluated the following findings on head CT scans: density, the presence of calcifications, hydrocephalus, hemorrhage, perilesional edema, topography, number and size of lesions, and the contrast-enhancement pattern. We evaluated the following on MR imaging: T1 and T2 signals and diffusion, perfusion, and spectroscopy findings.

Similar to Toh et $\mathrm{al}^{27}$ who studied the "dual rim sign" on SWI in pyogenic abscesses, we also evaluated patients with SWI sequences for the presence of the dual rim sign, which is defined as 2 concentric rims around the central cavities at the margins of lesions, with the outer rim being hypointense, and the inner rim, hyperintense relative to the cavity contents. All imaging findings were assessed by 1 neuroradiologist with 8 years of experience. In addition, the clinical symptoms were accessed through systematic chart review. 


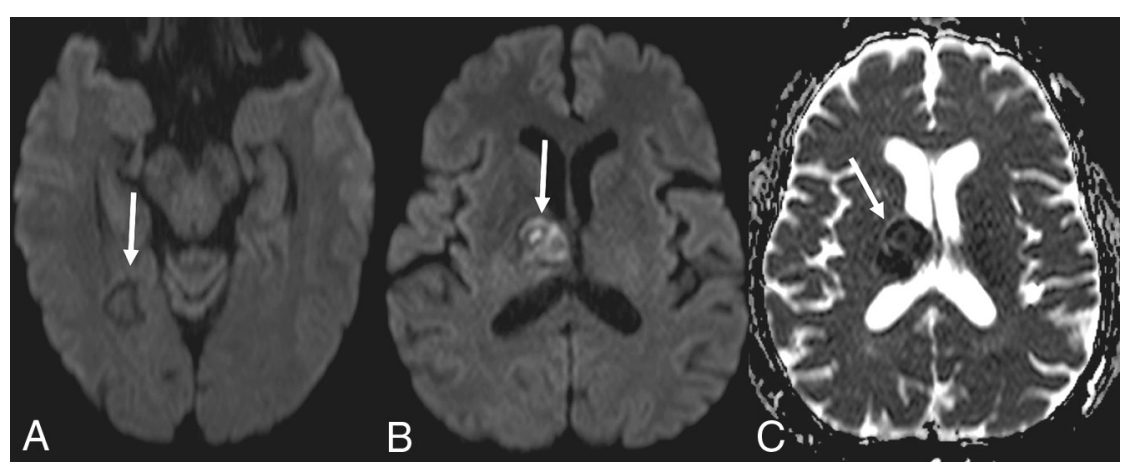

FIG 4. Demonstration that the lesions may not present with diffusion restriction $(A)$ or diffusion restriction (B) with a low signal on the ADC map (C).

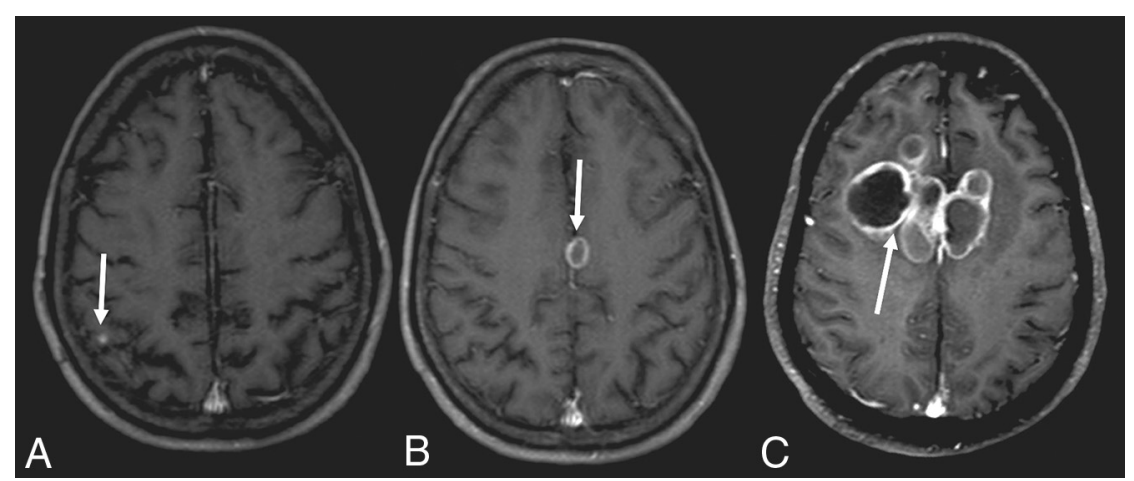

FIG 5. T1-weighted images after contrast administration demonstrating a small nodule in the cortical-subcortical transition $(A)$, nodular lesion with annular enhancement $(B)$, and multiple nodular lesions with annular enhancement and "daughter cysts" in a complex heterogeneous mass (C).

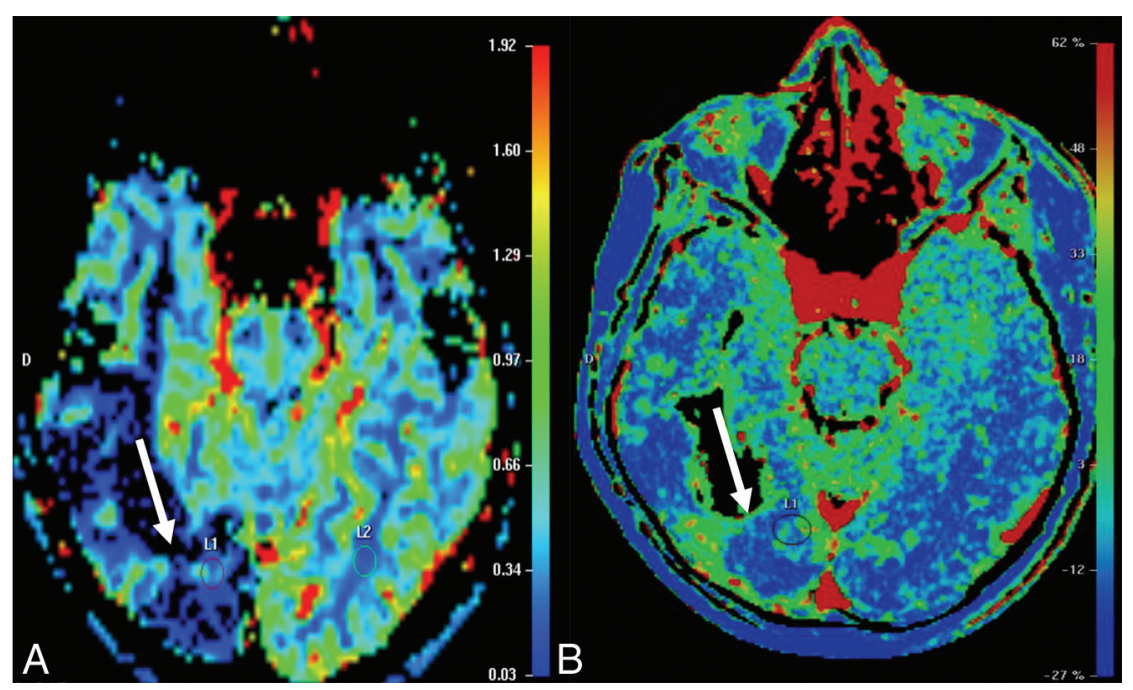

FIG 6. T2-weighted perfusion shows a lesion with low perfusion (A). T1-weighted perfusion shows the blood-brain barrier breakdown (B).

Furthermore, the study was approved by the Ethics Committee for Clinical Research of the University Hospital Cassiano Antônio de Moraes, Federal University of Espirito Santo, Espirito Santo, Brazil.

\section{RESULTS}

We describe 24 patients with a diagnosis of CNS PCM. All patients were men, ranging from 19 to 66 years of age. Approximately half of the patients were between 40 and 59 years of age. Headache was the most common neurologic symptom and was present in $33.3 \%$ of the cases. The epidemiology and clinical characteristics are summarized in Table 1.

Twenty-one patients had the pseudotumoral form, defined by the presence of parenchymal lesions with annular or nodular enhancement, while the meningeal pattern was observed in 1 case, and the combined form, in 2 cases. None of the patients had calcifications at the time of the initial neuroimaging. Perilesional edema was present in $90.4 \%$ of cases, whereas hydrocephalus and hemorrhage were found in $25 \%$ and $13 \%$ of cases, respectively. The number of lesions observed in each patient ranged from 1 to 11 , with a mean of 3 . Eleven patients had between 2 and 5 lesions (Table 2). Most were localized in the frontal lobe $(37.5 \%)$, followed by the cerebellum (33.3\%), parietal lobe (29.1\%), occipital lobe (25\%), and thalamus (20.8\%) (Table 3). Furthermore, $65.2 \%$ of the lesions had an axial diameter of $>2 \mathrm{~cm}$, and the larger axial diameter of the major lesion ranged from 0.3 to $5.6 \mathrm{~cm}$ (Table 2).

Seventeen patients had CT scans showing a total of 53 lesions, of which $56.6 \%$ were hypoattenuating, $20.7 \%$ were hyperattenuating, and $22.6 \%$ had a hypoattenuating center with a hyperattenuating margin (Table 2 and Fig 1). On the other hand, 19 patients underwent MR imaging, in which a total of 61 lesions were observed. The T1-weighted sequence demonstrated that $50.8 \%$ were hypointense, $34.4 \%$ were hyperintense, and $14.7 \%$ were heterogeneous with a hypointense center with a hyperintense margin (Fig 2). On the T2-weighted sequence, 59\% were hypointense, 9.8\% were hyperintense, and $31.1 \%$ had heterogeneous lesions (hyperintense + hypointense) (Fig 3). Restricted diffusion was present in $47.3 \%$ (Fig 4), and the target sign was observed in 1 patient (5.2\%). Ring contrast enhancement was observed in $70.8 \%$; nodular enhancement, in $12.5 \%$; both ring and nodular enhancement, in 12.5\%; and 
leptomeningeal enhancement, in $4.1 \%$ of the cases (Table 3 and Fig 5). Moreover, 3 patients underwent MR perfusion imaging, and 2 underwent proton spectroscopy. The perfusion demonstrated decreased relative CBV on DSC and slow and progressive ascending perfusion on dynamic contrast-enhanced imaging in all 3 patients (Fig 6). The spectroscopy demonstrated an increase of lipids and choline in both patients (Table 4 and Fig 7). Of the 5 patients in whom the SWI sequence was performed, 4 showed

\section{Table 4: MR imaging findings}

\begin{tabular}{|c|c|}
\hline Characteristic & Value \\
\hline \multicolumn{2}{|l|}{ MR imaging scans (No. of patients) (\%) ${ }^{a}$} \\
\hline \multicolumn{2}{|l|}{ T1-weighted ${ }^{\mathrm{b}}$} \\
\hline Hyperintense lesions & $21(34.4)$ \\
\hline Hypointense lesions & $31(50.8)$ \\
\hline \multicolumn{2}{|l|}{ Hypointense center and hyperintense margin } \\
\hline \multicolumn{2}{|l|}{ T2-weighted ${ }^{\mathrm{b}}$} \\
\hline Hyperintense lesions & $6(9.8)$ \\
\hline Hypointense lesions & $36(59.0)$ \\
\hline $\begin{array}{l}\text { Heterogeneous lesions (hyperintense }+ \\
\text { hypointense) }\end{array}$ & $19(31.1)$ \\
\hline \multicolumn{2}{|l|}{ T1, perfusion ${ }^{c}$} \\
\hline Slow and progressive ascending & $3(100)$ \\
\hline \multicolumn{2}{|l|}{ T2, perfusion ${ }^{c}$} \\
\hline Decreased rCBV & $3(100)$ \\
\hline \multicolumn{2}{|l|}{ Spectroscopyc } \\
\hline Decrease of NAA & $2(100)$ \\
\hline Increase of choline & $2(100)$ \\
\hline Increase of lipids & $2(100)$ \\
\hline \multicolumn{2}{|l|}{ Diffusion-weighted (No. of patients) (\%) ${ }^{d}$} \\
\hline Restricted diffusion & $9(47.3)$ \\
\hline Target sign & $1(5.2)$ \\
\hline
\end{tabular}

Note:- $r$ CBV indicates relative CBV.

${ }^{a}$ Five patients did not have MR imaging scans and were eliminated from the calculations.

${ }^{b}$ The patient with the meningeal form was eliminated from the calculations.

${ }^{c}$ Only 3 patients underwent perfusion, and only 2 underwent spectroscopy.

${ }^{d}$ Five patients did not have diffusion and were eliminated from the calculations. the dual rim sign on SWI (Fig 8). The patient who did not show the dual rim signal on SWI had a lesion $<2 \mathrm{~cm}$.

Thoracic imaging revealed that all patients presented with thoracic lesions in the form of pulmonary nodules, ground-glass opacities, consolidations, reversed halo sign, bronchiectasis, or lymph node enlargement.

\section{DISCUSSION}

To the best of our knowledge, this study presents the largest imaging case series of CNS PCM until now (Fig 9). We describe the neuroimaging findings from 24 patients who were treated in a reference hospital in the State of Espirito Santo.

Peçanha et $\mathrm{al}^{28}$ analyzed 546 patients in a reference hospital from 1978 to 2012 presenting with PCM. The historical case series revealed the involvement of the CNS in $4.5 \%$ (22 patients) with the chronic form and $3.3 \%$ (2 patients) with the acute/subacute form.

The main patterns of CNS PCM described are the pseudotumoral (90\%) and meningeal (10\%) forms. ${ }^{19-21,29}$ Moreover, meningitis associated with the pseudotumoral form may occur in $17 \%$ of cases, or more rarely, it can be an isolated finding. ${ }^{19}$ In our study, we also observed the predominance of the pseudotumoral form $(87.5 \%)$, while the meningeal form was observed in $4.1 \%$, and the combined form, in $8.3 \%$ of the cases.

The meningeal form is characterized by inflammation of the leptomeninges or pachymeninges, generally in the base of the skull, similar to what is observed in tuberculosis meningitis. ${ }^{18,29-33}$ It may be diffuse or localized, isolated, or with dissemination to the parenchyma or nervous roots.

On the other hand, the pseudotumoral form consists of intraparenchymal granulomas, involving both the supratentorial and infratentorial compartments, which may mimic primary tumors, metastases, pyogenic abscesses, or viral and fungal etiologies. ${ }^{20,34}$ The granulomas are frequently irregular (76\%), ranging from 10

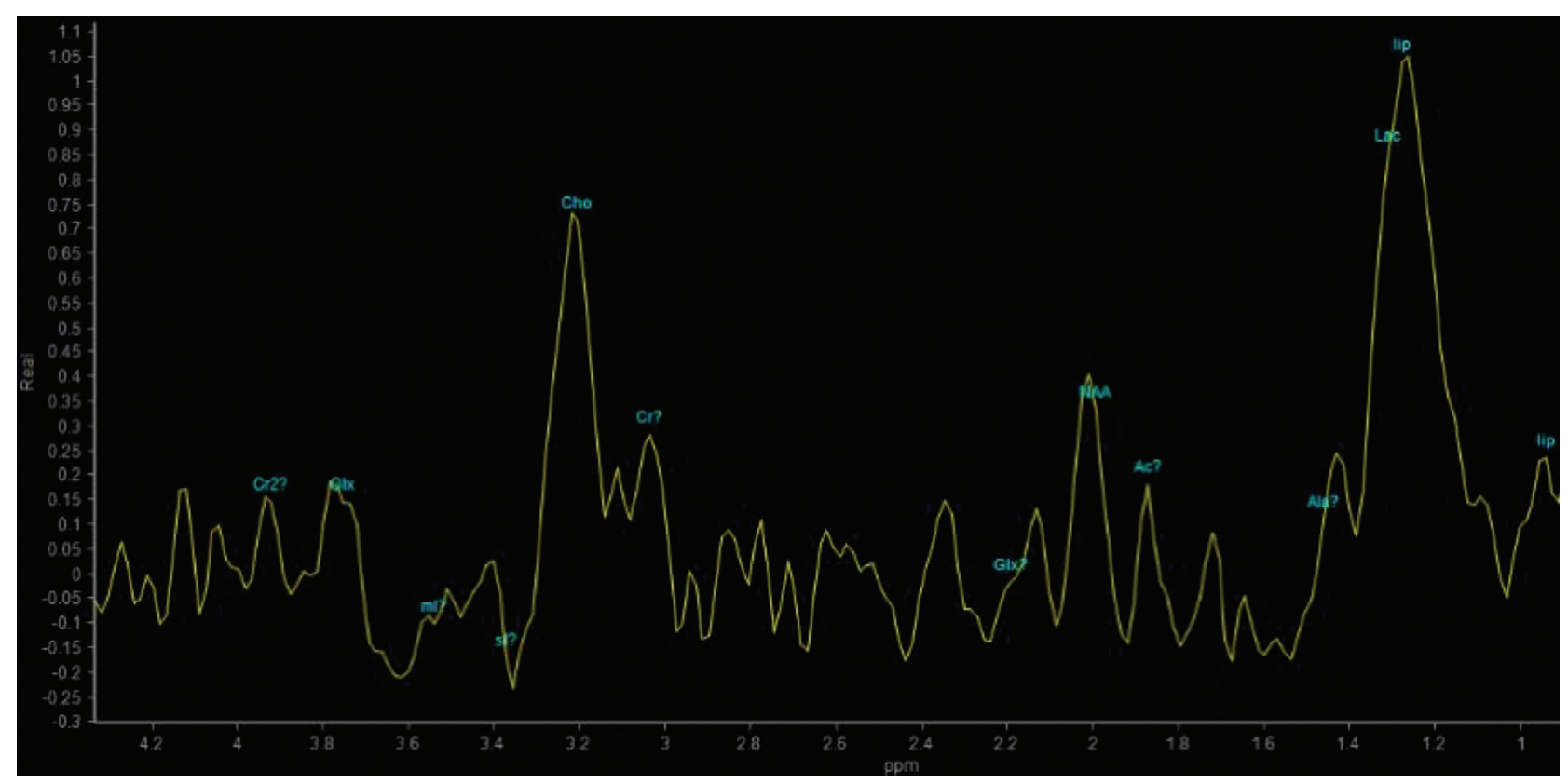

FIG 7. Proton spectroscopy with a TE = $144 \mathrm{~ms}$ showing increased lipid and choline peaks, with decreased NAA peaks. 
to $45 \mathrm{~mm}$, with mass effect, peripheral enhancement by contrast, and perilesional edema in $82 \%$ of the cases. ${ }^{20,29,32}$ In our study, $65.2 \%$ of the patients had a granuloma larger than $2.0 \mathrm{~cm}$; the mean diameter of the larger lesion was $2.3 \mathrm{~cm}$ with the range $0.3-5.6 \mathrm{~cm}$, showing the same irregularity described in other studies. Similar to the studies described in the medical literature, perilesional edema was present in $90.4 \%$ of our patients.

The lesion can be situated in the cerebral hemispheres (67\%), cerebellum (25\%), brain stem (25\%), and spinal cord (4\%). ${ }^{19,20}$ In our study, $62.5 \%$ of patients had lesions in the cerebral hemispheres; $33.3 \%$, in the cerebellum; and $8.3 \%$, in the brain stem; and no patient had a spinal cord lesion. Gasparetto et al ${ }^{20}$ demonstrated that $47 \%$ of patients had a singular granuloma, $23 \%$ had 2 lesions, and $30 \%$ had $\geq 3$ lesions. In our study, we observed a frequency similar to that of Gasparetto et al; $40.9 \%$ of the patients had a single granuloma. The mean number of lesions was 3 , and the range was $1-11$.

The location of the lesions determines the signals and symptoms in the patients. ${ }^{29,35}$ The 5 most frequent symptoms were epilepsy, hemiparesis, cerebellar signs, headache, and hydrocephalus. ${ }^{19,32}$ In our patients, the most common symptom was headache, followed by epilepsy.

The pseudotumoral form can assume a compact granulomatous pattern, which is completely solid, or it can have a necrotic center that explains the findings in the MR images. In addition, granulomas do not infiltrate or spread to the adjacent tissue. ${ }^{20}$ Therefore, necrotic lesions in PCM may resemble pyogenic abscesses, and proton MR imaging with spectroscopy being a noninvasive technique can help distinguish the lesions. ${ }^{36,37}$ Similar to Reis et $\mathrm{al}^{33}$ we found a high peak of the lipids and choline in all cases.

MR images show the pseudotumoral lesions consist of variable, hypo- or hyperintense lesions in T1 and T2 sequences. In particular, Reis et $\mathrm{al}^{33}$ described the presence of a peripheral hyperintense halo in the T1 sequences without contrast in all 8 patients who were included in their research. In our study, this finding was in only $14.7 \%$, demonstrating that it is not as frequent as reported in the above study.

Due to the variability of the composition of a granuloma, the diffusion-weighted sequence may exhibit lesions with or without restriction of water molecules. In our cases, $47.3 \%$ of patients had restriction on the diffusion imaging, showing variability as is described.

Similar to Toh et al, ${ }^{27}$ who found

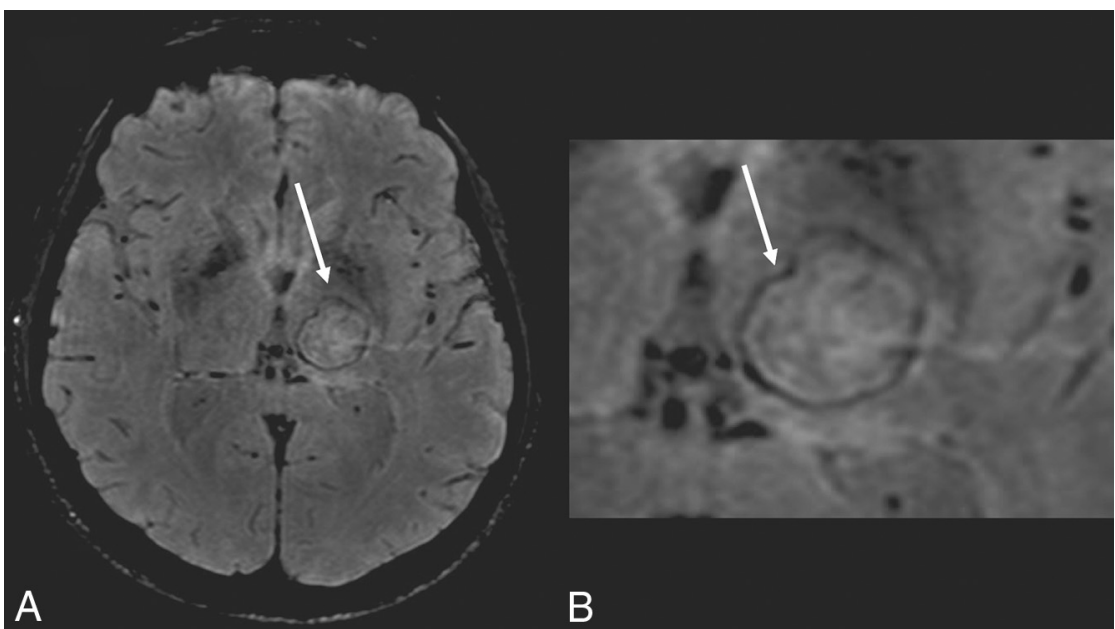

FIG 8. SWI sequence showing the dual rim sign. Note the external hypointense halo with an internal hyperintense halo. the dual rim sign on SWI in 9 of 12 patients with pyogenic abscesses, we found this sign in all our 4 patients who presented with lesions $>2 \mathrm{~cm}$ and underwent the SWI sequence, showing that this sign is not specific for pyogenic abscess. The contrast-enhancing rim of bacterial brain abscesses on MR imaging corresponds to the abscess capsule, and the magnetic susceptibility results from the free radicals produced by macrophages. There are a necrotic center and a zone of granulation tissue between the fibrocollagenous capsule and the center of the abscesses. With image coregistration,

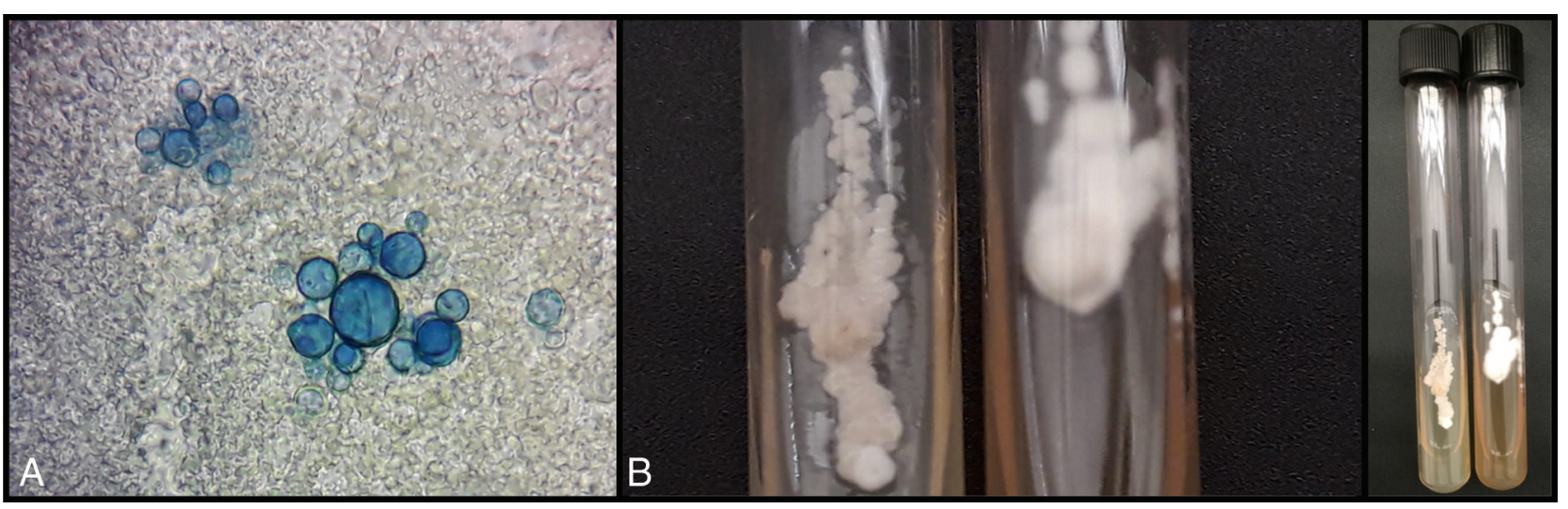

FIG 9. Laboratory diagnosis of paracoccidioidomycosis. Fresh examination in Parker-KOH stain shows yeast cells with multiple buds (A). Cultivation of Paracoccidioides spp. Left, yeast colonies to $37^{\circ} \mathrm{C}$; and right, filamentous colonies to $25^{\circ} \mathrm{C}(B)$. 
Toh et $\mathrm{al}^{27}$ speculated that the hyperintense rims probably represent granulation tissue in pyogenic abscesses. We think this finding, the dual rim, occurs because PCM is also an infection. We suspect that this signal may occur in other infections, not only in bacterial abscesses as initially described by Toh et al. Because an antifungal is the treatment form, histopathologic examination of the margins may not be available in most cases. Thus, this finding is limited by a lack of direct histopathologic correlation with SWI findings, making it difficult to precisely define its origin.

CT images of the pseudotumoral form usually show hypoattenuating lesions with ring enhancement after contrast administration and surrounding edema. Calcifications or septations within the lesions might occur in up to $20 \%$ of cases. ${ }^{20}$ With time, pseudotumoral CNS PCM gradually becomes more attenuating in noncontrast tomography and progressively becomes smaller. $^{20}$

PCM shows a typical granulomatous reaction consisting of multinucleated giant cells mixed with extensive interstitial and conglomerate fibrosis, necrosis, and arterial intimal fibrosis. It subsequently may develop a central area of necrosis, and this may explain the heterogeneous image pattern. The central area of necrosis is initially solid and later may liquefy. On CT, the solid granuloma, without necrosis, may present as isoattenuated or slightly hyperattenuated to the brain parenchyma. On MR imaging, it is hypointense on both T1- and T2WI. The heterogeneity of imaging findings show homogeneous enhancement on postcontrast images. Because the granuloma shows necrosis of its central portion, the images show hypoattenuated lesions on CT, hyperintense on T2WI, with ring enhancement on postcontrast images. Liquid necrotic lesions show restricted diffusion, whereas solid necrotic lesions do not have restriction of diffusion. ${ }^{15,20,33}$

Similar to Reis et $\mathrm{al}^{33}$ all our cases presented with thoracic lesions. Gasparetto et $\mathrm{al}^{20}$ also found thoracic alterations in most patients (88\%), a finding that may help in the differential diagnosis.

This study has limitations. Few patients were studied with advanced MR imaging methods like DSC, dynamic contrastenhancement, spectroscopy, and SWI, with only qualitative analyses, but it paves the way for new studies in the area that may contribute to additional findings in this disease.

\section{CONCLUSIONS}

CNS involvement has a variable frequency rate in PCM, and an increase in reports has been observed in recent years. ${ }^{19,26}$ The diagnosis of PCM in the CNS is difficult because of the low sensitivity of diagnostic tests, the isolated forms of PCM in the CNS, the absence of previous systemic infection, and nonspecific symptoms that may be confused with other entities. Nevertheless, imaging examinations though nonspecific, when combined with the epidemiology and clinical manifestations, can play an important role in the diagnosis and evaluation of the disease. Therefore, it should be considered as a differential diagnosis for expansive lesions in the brain or meningitis, particularly in endemic areas.

\section{REFERENCES}

1. Kwon-Chung KJ, Bennett JE. Medical mycology. Rev Inst Med Trop Sao Paulo 1992;34:504-04 CrossRef
2. Marques-da-Silva SH, Rodrigues AM, de Hoog GS, et al. Occurrence of Paracoccidioides lutzii in the Amazon region: description of two cases. Am J Trop Med Hyg 2012;87:710-14 CrossRef Medline

3. Turissini DA, Gomez OM, Teixeira MM, et al. Species boundaries in the human pathogen Paracoccidioides. Fungal Genet Biol 2017;106:9-25 CrossRef Medline

4. Bagagli E, Theodoro RC, Bosco SM, et al. Paracoccidioides brasiliensis: phylogenetic and ecological aspects. Mycopathologia 2008;165:197-207 CrossRef Medline

5. Terçarioli GR, Bagagli E, Reis GM. Ecological study of Paracoccidioides brasiliensis in soil: growth ability, conidia production and molecular detection. BMC Microbiol 2007;7:92 CrossRef Medline

6. Wanke B, Aide MA. Chapter 6: paracoccidioidomycosis. J Bras Pneumol 2009;35:1245-49 CrossRef Medline

7. Coutinho ZF, Silva D, Lazera M, et al. Paracoccidioidomycosis mortality in Brazil (1980-1995). Cad Saúde Pública 2002;18:1441-54 CrossRef Medline

8. Ajello L, Polonelli L. Imported paracoccidioidomycosis: a public health problem in non-endemic areas. Eur J Epidemiol 1985;1:16065 CrossRef Medline

9. Kamei K, Sano A, Kikuchi K, et al. The trend of imported mycoses in Japan. J Infect Chemother 2003;9:16-20 CrossRef Medline

10. Buitrago MJ, Cuenca-Estrella M. Current epidemiology and laboratory diagnosis of endemic mycoses in Spain [in Spanish]. Enferm Infecc Microbiol Clin 2012;30:407-13 CrossRef Medline

11. Laccourreye $\mathrm{O}$, Mirghani $\mathrm{H}$, Brasnu D, et al. Imported acute and isolated glottic paracoccidioidomycosis. Ann Otol Rhinol Laryngol 2010;119:89-92 CrossRef Medline

12. Onda H, Komine M, Murata S, et al. Letter: imported paracoccidioidomycosis in Japan. Dermatol Online J 2011;17:11 Medline

13. Van Damme PA, Bierenbroodspot F, Telgtt DS, et al. A case of imported paracoccidioidomycosis: an awkward infection in the Netherlands. Med Mycol 2006;44:13-18 CrossRef Medline

14. Walker SL, Pembroke AC, Lucas SB, et al. Paracoccidioidomycosis presenting in the U.K. Br J Dermatol 2007;158:624-26 CrossRef Medline

15. Rosa Junior M, Baldon IV, Amorim AFC, et al. Imaging paracoccidioidomycosis: a pictorial review from head to toe. Eur J Radiol 2018;103:147-62 CrossRef Medline

16. Martinez R. Epidemiology of paracoccidioidomycosis. Rev Inst Med Trop Sao Paulo 2015;57:11-20 CrossRef Medline

17. Benard G. An overview of the immunopathology of human paracoccidioidomycosis. Mycopathologia 2008;165:209-21 CrossRef Medline

18. Finamor LP, Muccioli C, Martins MC, et al. Ocular and central nervous system paracoccidioidomycosis in a pregnant woman with acquired immunodeficiency syndrome. Am J Ophthalmol 2002;134:456-59 CrossRef Medline

19. de Almeida SM, Queiroz-Telles F, Teive HA, et al. Central nervous system paracoccidioidomycosis: clinical features and laboratorial findings. J Infect 2004;48:193-98 CrossRef Medline

20. Gasparetto EL, Liu CB, de Carvalho Neto A, et al. Central nervous system paracoccidioidomycosis: imaging findings in 17 cases. $J$ Comput Assist Tomogr 2003;27:12-17 CrossRef Medline

21. Magalhaes AC, Bacheschi LA, Caramelli P, et al. Paracoccidioidomycosis of the central nervous system: study of 5 cases by magnetic resonance [in Portuguese]. Rev Hosp Clin Fac Med Sao Paulo 1993;48:94-97 Medline

22. Duarte AL, Baruffa G, Terra HB, et al. Systemic paracoccidioidomycosis with central nervous system involvement [in Portuguese]. Rev Soc Bras Med Trop 1999;32:439-42 CrossRef Medline

23. Correa RB, Puccioni-Sohler M, Artemenko SR, et al. An uncommon neurologic presentation in the course of paracoccidioidomycosis: report of a case [in Portuguese]. Arq Neuropsiquiatr 1991;49:456-59 CrossRef Medline 
24. de Moura LP, Raffin CN, del Negro GM, et al. Paracoccidioidomycosis evidencing spinal cord involvement treated with success by fluconazole [in Portuguese]. Arq Neuropsiquiatr 1994;52:82-86 CrossRef Medline

25. Pereira WC, Tenuto RA, Raphael A, et al. Brain localization of South American blastomycosis: considerations apropos of 9 cases [in Portuguese]. Arq Neuropsiquiatr 1965;23:113-26 CrossRef Medline

26. de Almeida SM. Central nervous system paracoccidioidomycosis: an overview. Braz J Infect Dis 2005;9:126-33 CrossRef Medline

27. Toh $\mathrm{CH}$, Wei $\mathrm{KC}$, Chang $\mathrm{CN}$, et al. Differentiation of pyogenic brain abscesses from necrotic glioblastomas with use of susceptibility-weighted imaging. AJNR Am J Neuroradiol 2012;33:1534-38 CrossRef Medline

28. Peçanha PM, Batista Ferreira ME, Massaroni PM, et al. Paracoccidioidomycosis: epidemiological and clinical aspects in 546 cases studied in the state of Espirito Santo, Brazil. Am J Trop Med Hyg 2017;97:836-44 CrossRef Medline

29. Elias J Jr, dos Santos AC, Carlotti CG Jr, et al. Central nervous system paracoccidioidomycosis: diagnosis and treatment. Surg Neurol 2005;63(Suppl 1):S13-21; discussion S21 CrossRef Medline

30. Pedro RDJ, Branchini ML, de Lucca RS, et al. Paracoccidioidomycosis of the central nervous system: apropos of 2 cases [in
Portuguese]. Rev Inst Med Trop Sao Paulo 1980;22:269-74 Medline

31. Lorenzoni PJ, Chang MR, Paniago AM, et al. Paracoccidioidomycosis meningitis: case report [in Portuguese]. Arq Neuropsiquiatr 2002;60:1015-18 CrossRef Medline

32. Francesconi F, Francesconi do Valle AC, Silva MT, et al. International issues: meningoencephalitis due to Paracoccidioides brasiliensis. Neurology 2008;71:e65-67 CrossRef Medline

33. Reis F, Collier PP, Souza TF, et al. Neuroparacoccidioidomycosis (NPCM): magnetic resonance imaging (MRI) findings. Mycopathologia 2013;175:181-86 CrossRef Medline

34. Rodacki MA, De Toni G, Borba LA, et al. Paracoccidioidomycosis of the central nervous system: CT findings. Neuroradiology 1995;37:636-41 CrossRef Medline

35. Teive HA, Zanatta A, Germiniani FM, et al. Holmes' tremor and neuroparacoccidioidomycosis: a case report. Mov Disord 2002;17:1392-94 CrossRef Medline

36. Faria AV, Dabus GC, Zanardi VA, et al. Proton magnetic resonance spectroscopy and magnetic resonance imaging findings in a patient with central nervous system paracoccidioidomycosis. $J$ Neuroimaging 2004;14:377-79 CrossRef Medline

37. Magalhaes AC, Caramelli P, Silva ED, et al. Magnetic resonance imaging in intracranial paracoccidioidomycosis. J Neuroimaging 1993;3:216-19 CrossRef Medline 